\title{
Research article \\ Prevalence of osteopenia and osteoporosis among the population of southern Kyrgyzstan - A cross-sectional observational study
}

\author{
Tugolbai Tagaev ${ }^{1}$, Farida Imanalieva ${ }^{1}$, Sagynali Mamatov ${ }^{1}$, Yethindra Vityala ${ }^{2}$, Altynai Zhumabekova ${ }^{3}$ \\ ${ }^{1}$ Department of Hospital Internal Medicine, Occupational Pathology with a Course of Hematology, I.K. Akhunbaev Kyrgyz \\ State Medical Academy, Bishkek, Kyrgyzstan \\ ${ }^{2}$ Department of Pathology, International Higher School of Medicine, International University of Kyrgyzstan, Bishkek, \\ Kyrgyzstan \\ ${ }^{3}$ Obstetrician-Gynecologist, City Maternity Hospital No. 2, Bishkek, Kyrgyzstan
}

(Received: October 2021 Revised: October $2021 \quad$ Accepted: November 2021)

Corresponding author: Tugolbai Tagaev. Email: ttagaev22.kg@gmail.com

\begin{abstract}
Introduction and Aim: Osteoporosis is a skeletal disorder characterized by diminished bone strength that increases the risk of fracture in instances of trivial trauma. The objective was to conduct ultrasound bone densitometry in different age groups (18-60 years and older) in southern Kyrgyzstan, to identify and study the prevalence of osteopenia and osteoporosis.
\end{abstract}

Materials and Methods: In this cross-sectional observational study a total of 1200 participants were included, where 580 men and 620 women were aged between 18-60 years and older. Based on the age, the participants were divided into three groups. Bone mineral density in participants was measured using a SONOST-3000 densitometer model. The study was conducted among the population of the Osh and Jalal-Abad regions.

Results: Among the population of Osh state in the first group, normal values were found in $65.0 \%$, osteopenia in $26.0 \%$, and osteoporosis in $9.0 \%$ of participants. In the second group, values were significantly higher than in the first group. In the third age group, values exceeded significantly compared to the first and second groups. Similar data were obtained from the population of Jalal-Abad state, but a significant difference was found in the elderly people group with a higher percentage of osteopenia and osteoporosis.

Conclusion: The results showed the prevalence of osteopenia and osteoporosis in participants of different age categories of Osh and Jalal-Abad states, and especially in the elderly. Depending on the gender distribution, the prevalence of osteopenia and osteoporosis in our study is significantly higher in women than in men.

Keywords: Osteopenia; osteoporosis; bone mineral density; ultrasound bone densitometry; Kyrgyzstan.

\section{INTRODUCTION}

$\mathrm{O}$ steoporosis is a skeletal disorder characterized by diminished bone strength that increases the risk of fracture in instances of trivial trauma (1). However, since it is asymptomatic, it cannot be diagnosed until a fracture occurs $(2,3)$. It involves osteoporotic fractures, and not only osteoporosis but leads to noticeable clinical and economic consequences $(2,4)$. The World Health Organization (WHO) estimates the lifetime risk of osteoporotic fracture of the hip, vertebra, or wrist from 30 to $40 \%$ in developed countries (2). The prevalence of osteoporosis in 27 countries of the European Union among people over 50 years of age is $15 \%$ (22\% in women and $6.6 \%$ in men) $(3,4)$, and the European Prospective Osteoporosis Study estimated the prevalence of osteoporosis is $15 \%$ in women aged 50 to 60 years and $45 \%$ in women over 70 years (5). In men, the prevalence estimated in European Prospective Osteoporosis Study was $2.4 \%$ between the ages of 50 and 60 and $17 \%$ over the age of 70 (5).

Osteoporosis has been associated with increased mortality and decreased health-related quality of life (6-8). In most cases, osteoporosis is asymptomatic, so it is difficult to suspect it in the absence of fractures, which is why it often remains undiagnosed. This phenomenon is particularly characteristic of Kyrgyzstan, as the problem remains poorly understood. There are no official statistics on the prevalence of this disease among the population of Kyrgyzstan, many aspects of its etiology and pathogenesis have not been definitively clarified together with dependence on risk factors.

In recent years, attempts have been made in Kyrgyzstan to study the epidemiology of osteopenia and osteoporosis in the country. So, in 2018, the staff of the Department of Hospital Internal Medicine, Occupational Pathology with a course of Hematology of the I. K. Akhunbaev Kyrgyz State Medical Academy conducted research on the prevalence of osteoporosis in the population of people in Bishkek, Kyrgyzstan (9). According to their data, in the study of 729 people, osteopenia was detected in $44.5 \%$ of people, and osteoporosis in $11 \%$ of people, which indicates that there is a sufficient prevalence, regardless of age category. This circumstance prompted us to continue research on the prevalence of osteoporosis in southern Kyrgyzstan. An 
understanding of bone mineral density (BMD) pattern in the population is crucial for prevention, diagnosis of osteoporosis, and management of its complications further (10).

The objective of our study was to conduct ultrasound bone densitometry in different age groups (18-60 years and older) in southern Kyrgyzstan, to identify and study the prevalence of osteopenia and osteoporosis.

\section{MATERIALS AND METHODS}

This is a cross-sectional observational study with recruitment conducted from February 2019 to November 2019. A total of 1200 participants were included in this study. There are 600 participants recruited from the city of Osh (Osh state) and similarly, 600 participants recruited from the city of
Jalal-Abad (Jalal-Abad state). The participants (580 men and 620 women) were aged between 18-60 years and older. Based on the age, the participants were divided into three groups (Table 1). The inclusion criteria include men and women aged over 18 or over from southern regions of Kyrgyzstan, being in a situation of clinical stability, and having signed informed consent. The exclusion criteria include a list of abnormalities such as pathology of the musculoskeletal system (even rheumatoid arthritis), diseases affecting the bone metabolism (in the past or present), prolonged use (more than one month) of any drugs capable of changing the bone remodelling, repeated fractures of skeletal bones in participants and family, diseases of the endocrine system, neoplastic diseases, malabsorption syndrome, alcoholism, and occupational pathology.

Table 1: Characteristics of the examined participants

\begin{tabular}{|c|c|c|c|c|}
\hline Age groups & $\begin{array}{c}\text { Age of the } \\
\text { subjects }\end{array}$ & $\begin{array}{c}\text { The total number of } \\
\text { subjects surveyed in } \\
\text { the city of Osh }\end{array}$ & $\begin{array}{c}\text { The total number of } \\
\text { subjects surveyed in } \\
\text { the city of Jalal-Abad }\end{array}$ & Total \\
\hline $\begin{array}{c}\text { First group } \\
(\mathbf{1 8}-\mathbf{3 9} \text { years old) }\end{array}$ & $18-39$ years & $200(33.3 \%)$ & $200(33.3 \%)$ & $400(33.3 \%)$ \\
\hline $\begin{array}{c}\text { Second group } \\
(\mathbf{4 0 - 5 9} \text { years old) }\end{array}$ & $40-59$ years & $240(40.0 \%)$ & $240(40.0 \%)$ & $480(40.0 \%)$ \\
\hline $\begin{array}{c}\text { Third group } \\
\text { ( } \mathbf{6 0} \text { years) }\end{array}$ & $\geq 60$ years & $160(26.7 \%)$ & $160(26.7 \%)$ & $320(26.7 \%)$ \\
\hline \multicolumn{2}{|c|}{ Total } & $\mathbf{6 0 0 ( 5 0 . 0 \% )}$ & $\mathbf{6 0 0}(\mathbf{5 0 . 0 \%})$ & $\mathbf{1 2 0 0 ( 1 0 0 \% )}$ \\
\hline
\end{tabular}

BMD in participants was measured using a SONOST-3000 densitometer model (OsteoSys Co., Ltd, Seoul Korea). The study was conducted among the population of the Osh and Jalal-Abad regions. Eligible participants were assigned a cover letter describing the research, along with the survey instrument. All participants provided written informed consent before participating in the study. Confidentiality was maintained concerning data collected from participants. This study was approved by the I.K. Akhunbaev Kyrgyz State Medical Academy ethics committee (Protocol no. 15).

Statistical analysis was performed using Excel.XLSTAT v2020.1 (Microsoft, Addinsoft, Paris, France) and Statistica v8.0 (StatSoft Inc., Tulsa, USA). Parametric and nonparametric analysis methods, descriptive statistics with median calculation, $25 \%$, and $75 \%$ quartiles were used. To determine the mutual influence of indicators, Spearman's correlation analysis was used (to determine the relationship between qualitative and quantitative indicators, the Spearmen's correlation coefficient) and Pearson's (to determine the mutual influence between quantitative indicators). The Mann-Whitney test was used to assess the significance of differences between the groups. A two-sided $\mathrm{p}<0.05$ was considered statistically significant.

\section{RESULTS}

In this study, after conducting ultrasound densitometry in the population of the Osh region showed that in the first group of 130 participants, the average values of the $\mathrm{T}$-score and $\mathrm{Z}$-score were within the normal range $(-0.387$ and -0.318 , respectively). In 52 participants, the average values of the T- and Z-score were -1.511 and -1.605 , which indicates osteopenia, and in 18 participants, the average values of the $\mathrm{T}$ - and $\mathrm{Z}$-score were -2.4 and 2.5, which indicates osteoporosis. Thus, in the first group, normal BMD values were observed in $65 \%$, osteopenia in 26\%, and osteoporosis in $9 \%$ of participants (Table 2).

Table 2: Ultrasound densitometry in the population of the city of Osh

\begin{tabular}{|c|c|c|c|c|}
\hline $\begin{array}{c}\text { Indicators of } \\
\text { densitometry }\end{array}$ & $\begin{array}{c}\text { Normal values: } \\
\text { T- and Z-score to } \\
\mathbf{- 1 . 0}\end{array}$ & $\begin{array}{c}\text { Osteopenia: T- and } \\
\text { Z-score from -1.1 } \\
\text { to -2.5 }\end{array}$ & $\begin{array}{c}\text { Osteoporosis: T- } \\
\text { and Z-score are - } \\
\mathbf{2 . 5} \text { or less }\end{array}$ & Total (n) \\
\hline $\begin{array}{c}\text { First group } \\
(\mathbf{1 8}-\mathbf{3 9} \text { years old) }\end{array}$ & $130(65.0 \%)$ & $52(26.0 \%)$ & $18(9.0 \%)$ & 200 \\
\hline Second group & $98(40.8 \%)^{*}$ & $102(42.5 \%) *$ & $40(16.7 \%)^{*}$ & 240 \\
\hline
\end{tabular}




\begin{tabular}{|c|c|c|c|c|}
\hline $\begin{array}{c}\text { (40-59 years old) } \\
\text { Third group } \\
\text { ( } \geq \mathbf{6 0} \text { years) }\end{array}$ & $39(24.4 \%) * *$ & $84(52.5 \%) * *$ & $37(23.1 \%)^{* *}$ & 160 \\
\hline Total & $\mathbf{2 6 7}$ & $\mathbf{2 3 8}$ & $\mathbf{9 5}$ & $\mathbf{6 0 0}$ \\
\hline$*-\mathrm{p}<0.05-$ the differences are statistically significant compared to the first group \\
$* *-\mathrm{p}<0.05-$ the differences are statistically significant compared to the first and second groups \\
\hline
\end{tabular}

In the second group, 98 participants had average Tand $\mathrm{Z}$-score within the normal range $(0.280$ and 0.645 , respectively). In 102 participants, the average values of $\mathrm{T}$ - and $\mathrm{Z}$-score were -1.619 and -1.344 , respectively, which indicates osteopenia. In the remaining 40 participants, the $\mathrm{T}$ - and Z-score were 2.5 or less and averaged from -2.55 and -2.83 , respectively, which indicates osteoporosis. Thus, in this group, normal values were detected in $40.8 \%$, osteopenia in $42.5 \%$, and osteoporosis in $16.7 \%$ of participants, which is significantly higher than in the first group of the study (Table 2), which means an increase in the number of participants with osteoporosis with age.

In our study, the third group consisted of 160 elderly participants $(\geq 65$ years old). The following results were obtained: in 39 participants, the average indicators of the $\mathrm{T}$ - and Z-scores were within the normal range above -1.0 (average values -0.3 and 1.3, respectively), in 84 participants in the range from 1.1 to -2.5 (average values -1.83 and -0.928 ), and in the remaining 37 participants the values were below -
2.5 (mean values -2.833 and -2.467) (Table 2). This means that with ultrasound densitometry, osteopenia was detected in $52.5 \%$ and osteoporosis in $23.1 \%$ of elderly people. Despite their advanced age, $24.4 \%$ of this group had no signs of osteopenia, further research is required in this region because of the small sample size in this group.

Ultrasound densitometry was performed in 600 participants of the city of Jalal-Abad. The results obtained showed that in the first group of 137 participants, the average values of the T- and Z-score were -0.312 and -0.261 , respectively, and which indicates normal values. In 51 participants, the average values of $\mathrm{T}$ - and $\mathrm{Z}$-score were $-1,493$ and 1,575 , respectively, that is, they had osteopenia and in 12 participants, the average indicators of the $\mathrm{T}$ score were -2.4 , and the Z-score was 2.6, it was attributed to osteoporosis. Thus, in the first group, normal BMD values were detected in $68.5 \%$, osteopenia in $25.5 \%$, and osteoporosis in $6.0 \%$ of participants (Table 3 ).

Table 3: Ultrasound densitometry in the population of the city of Jalal-Abad

\begin{tabular}{|c|c|c|c|c|}
\hline $\begin{array}{l}\text { Indicators of } \\
\text { densitometry }\end{array}$ & $\begin{array}{c}\text { Normal values: } \\
\text { T- and Z-score to } \\
-\mathbf{- 1 . 0} \\
\end{array}$ & $\begin{array}{c}\text { Osteopenia: } T \text { - and } \\
\text { Z-score from }-1.1 \\
\text { to }-2.5\end{array}$ & $\begin{array}{c}\text { Osteoporosis: } T \text { - } \\
\text { and } Z \text {-score are - } \\
2.5 \text { or less }\end{array}$ & Total (n) \\
\hline $\begin{array}{c}\text { First group } \\
\text { (18-39 years old) }\end{array}$ & $137(68.5 \%)$ & $51(25.5 \%)$ & $12(6.0 \%)$ & $137(68.5 \%)$ \\
\hline $\begin{array}{c}\text { Second group } \\
(40-59 \text { years old })\end{array}$ & $82(34.1 \%) *$ & $107(44.6 \%)^{*}$ & $51(21.2 \%)^{*}$ & $82(34.1 \%)^{*}$ \\
\hline $\begin{array}{l}\text { Third group } \\
\text { ( } \geq 60 \text { years) }\end{array}$ & $17(10.6 \%)^{* *}$ & $97(60.7 \%)^{* * *}$ & $46(28.7 \%)^{* *}$ & $17(10.6 \%)^{* *}$ \\
\hline Total & 246 & 245 & 109 & 600 \\
\hline
\end{tabular}

In the second group, 82 participants had average $T$ and Z-score within the normal range $(-0.381$ and 0.131 , respectively). In 107 participants, the average values of $\mathrm{T}$ - and $\mathrm{Z}$-score were -1.748 and -1.557 , respectively, which indicates osteopenia. In the other 51 participants the $\mathrm{T}$ - and Z-score were below -2.5 and had average values between -2.888 and -2.833 , which indicates osteoporosis. Thus, in this group, normal values were detected in $34.1 \%$, osteopenia in $44.6 \%$, and osteoporosis in $28.7 \%$ of participants (Table 3).

The third group in our study consists of 160 elderly participants $(\geq 65$ years old). The results showed that in 17 participants, the average $\mathrm{T}$ - and $\mathrm{Z}$-score were within the range of -0.725 and 0.625 , respectively, which were attributed to the normal values, in 97 participants within the range of -1.746 and -0.863 , which indicates osteopenia, and in the remaining 46 participants, the average values were -2.833 and -2.3 , which indicates osteoporosis. In this group, $10.6 \%$ of the values corresponded to normal values, $60.6 \%$ to osteopenia and $28.7 \%$ to osteoporosis.

We conducted a comparative analysis of the data obtained in two areas: in the first and in the second group (18-39 years and 40-59 years) for all the compared categories "normal", "osteopenia" and "osteoporosis", there was no significant difference. As shown in Figure 1, there was a significant difference in the third group ( $\geq 60$ years), where the elderly participants of the city of Jalal-Abad had higher rates of "osteopenia" and "osteoporosis", but the "normal" values were significantly reduced ( $p$ $<0.05)$. 


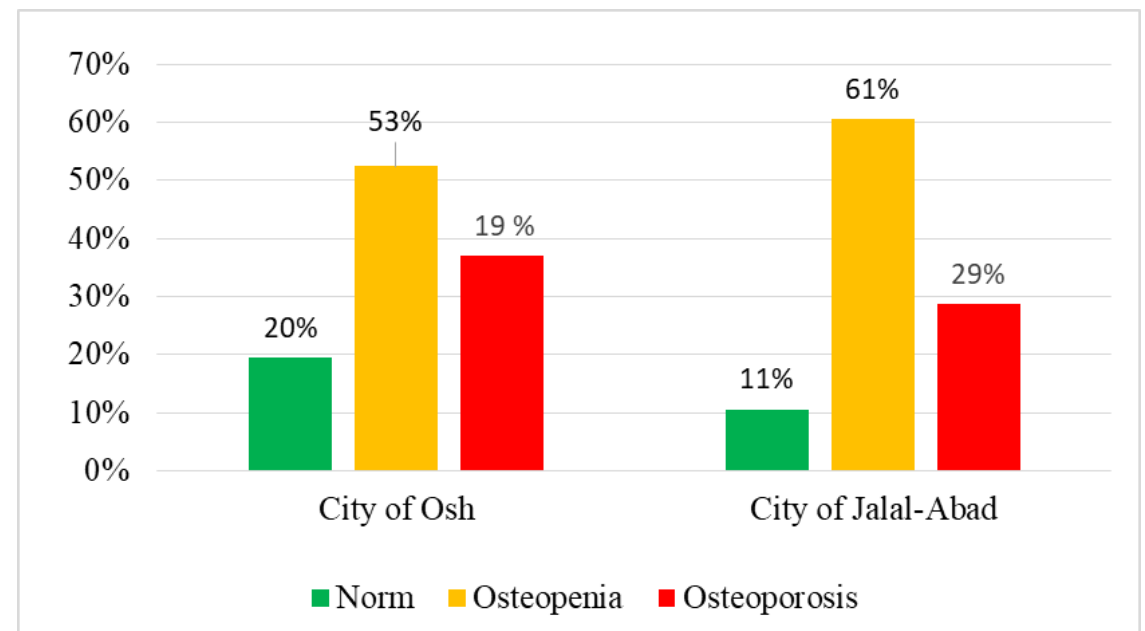

Fig. 1: Comparative data of ultrasound densitometry in elderly people ( $\geq 60$ years old) in the cities of Osh and Jalal-Abad

We also analysed ultrasound densitometry data depending on the gender distribution (Fig. 2). Thus, out of 580 men, BMD values were normal in 295 (50.9\%), osteopenia was diagnosed in 209 (36.0\%), and osteoporosis in $76(13.1 \%)$ participants. Out of 620 women, normal BMD values were found in 201 (32.4\%) women, osteopenia was observed in 281 (45.3\%), and osteoporosis in 138 (22.3\%) of them.

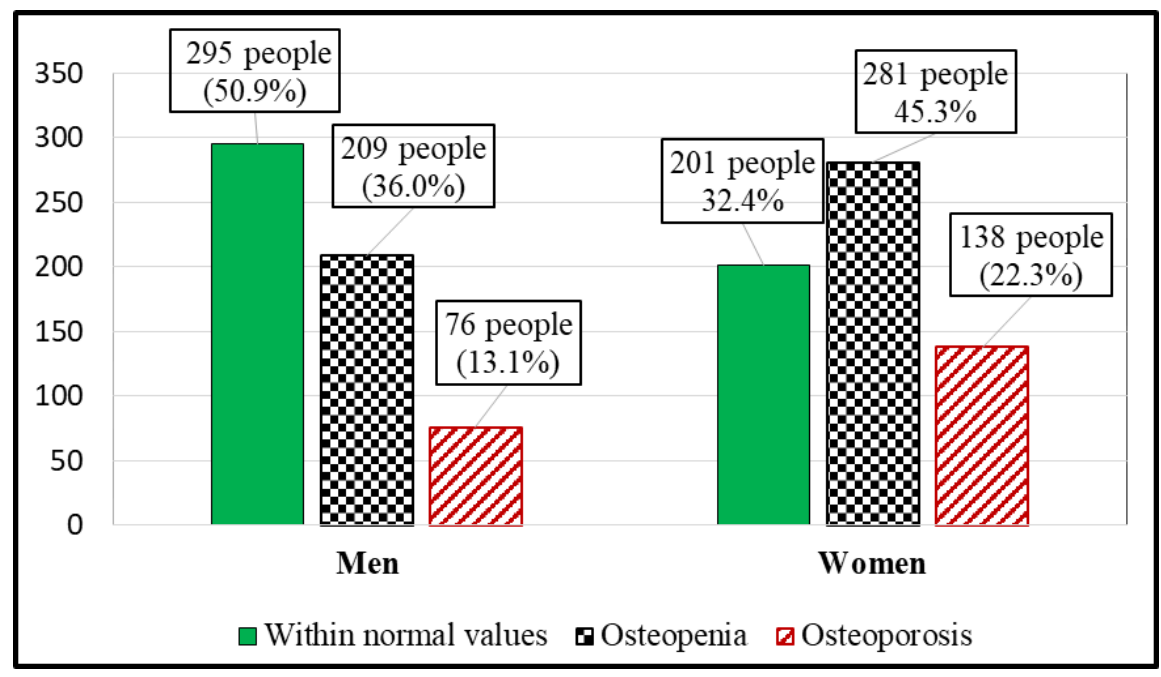

Fig. 2: Ultrasound densitometry data depending on gender.

As can be seen from figure 2, the results obtained indicate that the prevalence of osteopenia and osteoporosis in our study is significantly higher in women than in men $(\mathrm{p}<0.05)$.

\section{DISCUSSION}

According to the WHO recommendation (5), since 1994, the study of BMD allows not only to diagnose osteoporosis (reduction to -2.5 according to the $\mathrm{T}$ score) but also to assess the severity of osteoporosis (reduction to -2.5 according to the T-score and a lowtraumatic fracture). In our study, the following criteria for the diagnosis of osteoporosis based on a decrease in BMD were used as a basis: Any score upward of -1 is considered normal. Scores between -1 and -2.5 denote osteopenia. Results less than -2.5 suggest osteoporosis and lower with the presence of one or more fractures (11).

Similar studies were conducted by the Kazakh Academy of Nutrition and the Kazakh National Medical University named after S.D. Asfendiyarov in 2011 (12), but their results were inconsistent with our data. So, in their study, both women and men are equally susceptible to a decreased BMD, whereas, in our study, women have significantly high numbers of osteopenia and osteoporosis. The severity of osteopenia in the work of Kazakh people was $74.4 \%$, of which osteoporosis was $22.2 \%$, in our study this indicator is significantly lower.

One of the most pressing demographic problems peculiars to developed countries is the continuing aging of the population $(13,14)$. According to the $\mathrm{UN}$, the share of 65-year-old people will be exceeded $9 \%$, by 2025 there will be more than 800 million people $\geq 65$ in the world, which will be about $10 \%$ of the population, and by 2050 this may reach $16 \%$ (15). This means that the number of people in the age group $\geq 65$ years will grow at a high rate compared to other age groups. A meta-analysis of studies published from 2010 to 2016 on observational epidemiology studies in China reported that the total, men, and women prevalence of osteoporosis at the age $\geq 60$ years was $36 \%, 23 \%$, and $49 \%$, respectively (16). 
The population of Kyrgyzstan is gradually approaching the threshold of old age: at the beginning of 2020, 301 thousand, or $4.7 \%$ of the Kyrgyz population were aged $\geq 65$ years. Nevertheless, this share is significantly lower than that of other countries that are members of the Eurasian Economic Union.

This demographic process inevitably entails a change in the structure of morbidity, namely, an increase in the proportion of low-energy fractures. As a rule, the diagnosis of "osteoporosis" is made only after a bone fracture occurs, which entails large material costs in the field of healthcare.

Our study clearly showed that with age, the situation of osteopenia and osteoporosis in the country will only worsen. At the same time, osteopenia and osteoporosis have a sufficient prevalence not only in the elderly population, but they also affect younger people regardless of age.

\section{CONCLUSION}

According to ultrasound densitometry, the frequency of detection of osteopenia and osteoporosis in the population of the Osh state was recorded the highest in older age groups. At the age of 40-59 years, osteopenia was $42.5 \%$, osteoporosis $16.7 \%$, and in the group of $\geq 60$ years, osteopenia was detected in $52.5 \%$, osteoporosis in $23.1 \%$. The frequency of detection of osteopenia and osteoporosis in the age groups from 18-59 years was approximately like the population of the Osh state, but a significant difference was found in the category of elderly people ( $\geq 60$ years), where the indicators of osteopenia and osteoporosis were higher. Depending on the gender distribution, the prevalence of osteopenia and osteoporosis in our study is significantly higher in women than in men. Our study showed that the screening examination carried out using ultrasound densitometry should be continued throughout the country, which is necessary to develop a strategy for the prevention of osteopenia and osteoporosis in Kyrgyzstan.

\section{ACKNOWLEDGEMENT}

The authors acknowledge their patients for kind cooperation and for providing consent.

\section{CONFLICT OF INTEREST}

The authors declare no conflicts of interest

\section{REFERENCES}

1. Siris, E. S., Adler, R., Bilezikian, J., Bolognese, M., Dawson-Hughes, B., Favus, M. J., Harris, S. T., et al., The clinical diagnosis of osteoporosis: a position statement from the National Bone Health Alliance Working Group. Osteoporos Int. 2014; 25(5): 1439-1443.

2. World Health Organization. WHO scientific group on the assessment of osteoporosis at primary health care level: Summary Meeting Report, Brussels, Belgium, 5-7 May 2004; 2004.
3. Muñoz-Torres, M., Varsavsky, M., Avilés Pérez, M. D. Osteoporosis. Definition. Epidemiology. Rev Osteoporos Metab Miner. 2010; 2(3) suplemento:5-7.

4. Hernlund, E., Svedbom, A., Ivergård, M., Compston, J., Cooper, C., Stenmark, J., et al., Osteoporosis in the European Union: medical management, epidemiology, and economic burden. A report prepared in collaboration with the International Osteoporosis Foundation (IOF) and the European Federation of Pharmaceutical Industry Associations (EFPIA). Arch Osteoporos. 2013; 8(1): 136.

5. European Prospective Osteoporosis Study (EPOS) Group, Felsenberg, D., Silman, A. J., Lunt, M., Armbrecht, G., Ismail, A. A., Finn, J. D., et al., Incidence of vertebral fracture in europe: results from the European Perspective Osteoporosis Study (EPOS). J Bone Miner Res. 2002; 17(4): 716-724.

6. Cosman, F., de Beur, S. J., LeBoff, M. S., Lewiecki, E. M., Tanner, B., Randall, S., et al., Clinician's Guide to Prevention and Treatment of Osteoporosis. Osteoporos Int. 2014; 25(10): 2359-2381.

7. Kling, J. M., Clarke, B. L., Sandhu, N. P. Osteoporosis prevention, screening, and treatment: a review. Journal of women's health. J Womens Health (Larchmt). 2014; 23(7): 563-572.

8. Leslie, W. D., Morin, S. N. Osteoporosis epidemiology 2013: implications for diagnosis, risk assessment, and treatment. Curr Opin Rheumatol. 2014; 26(4): 440-446.

9. Imanalieva, F. E., Arstanbekova, M. A., Mamatov, S. M. The prevalence of osteopenic syndrome and osteoporosis in the population of Bishkek. Herald of KRSU. 2019; 19(5): $10-14$.

10. Agrawal, T., Verma, A. K. Cross sectional study of osteoporosis among women. Med J Armed Forces India. 2013; 69(2): 168-171.

11. Schousboe, J. T., Shepherd, J. A., Bilezikian, J. P., Baim, S. Executive summary of the 2013 International Society for Clinical Densitometry Position Development Conference on bone densitometry. J Clin Densitom. 2013; 16(4): 455-466.

12. Murzaevich, M. S., Imanalieva, F., Uulu, C. M., Tagaev, T., Yethindra, V., Arstanbekovna, M. Prevalence of Osteopenia and Osteoporosis in the Kyrgyz Republic. Indian J Forensic Med Toxicol. 2020; 14(3): 2016-2020.

13. Kanis, J. A., on behalf of the WHO Scientific Group. Assessment of osteoporosis at the primary health-care level. Technical Report. World Health Organization Collaborating Centre for Metabolic Bone Diseases, University of Sheffield, UK; 2008: 337 p.

14. Kanström, L., Zamaro, G., Sjostedt, C., Green, G. Healthy ageing profiles: guidance for producing local health profiles for older people. Copenhagen: World Health Organization Regional Office for Europe; 2008.

15. 2019 Revision and United Nations, Department of Economic and Social Affairs, Population Division. World Population Prospects 2019; 2019. Online Edition.

16. He, L., Sun, Y., Yao, W., Pan, K. The prevalence rate of osteoporosis in the elderly in China between 2010 and 2016: a meta-analysis of single rate. Chin J Osteoporos. 2016; 22(12): 1590-1596. 